\title{
Perlindungan Hukum Investor Pasar Modal Dalam Kepailitan Perusahaan Emiten
}

\author{
Krista Yitawati ${ }^{1}$, Hery Sumanto ${ }^{2}$ \\ ${ }^{1}$ Fakultas Hukum, Universitas Merdeka Madiun, Jl. SerayuNo.79, Madiun, 63133 \\ E-mail: krista@unmer-madiun.ac.id \\ ${ }^{2}$ Fakultas Hukum, Universitas Merdeka Madiun, Jl. SerayuNo.79, Madiun, 63133 \\ E-mail: herysumanto@unmer-madiun.ac.id
}

\begin{abstract}
The capital market is an investment alternative for investors. Through the capital market, investors can invest in several companies through the purchase of securities offered. Investors will become shareholders in publicly-listed companies. The purpose of this study is about the position of capital market investors in the event of bankruptcy in the issuer's company and know the form of protection that can provide protection for capital market investors. The research method used is a normative research method by reviewing legislation. the position of capital market investors in the event of bankruptcy in the issuer's company is that the public shareholders are creditors who are included in the competitor (concurrent) while the form of legal protection needed is to maximize the functions and roles of OJK as the protectors of the issuer's stock which is accurately related to the performance and financial condition of public companies because the principle of openness is one of the rights that guarantees legal protection, and makes efforts to restructure the issuer's company to avoid bankruptcy.
\end{abstract}

Keywords -: legal protection; investors; capital market; bankruptcy; issuers.

\section{PENDAHULUAN}

Pengertian pasar modal dalam Undang-Undang Nomor 8 Tahun 1995 Tentang Pasar Modal dapat disimpulkan bahwa segala hal yang berkaitan dengan jual beli efek dan penawaran umum, perusahaan publik dan semua lembaga dan profesi yang berhubungan dengan efek. ${ }^{1}$ Sedangkan yang dimaksud dengan efek adalah surat berharga, yaitu surat pengakuan hutang, surat berharga komersial, saham, bukti utang, obligasi, kontrak investasi kolektif, kontrak berjangka, dan efek derevatif. Investor dapat melakukan investasi di beberapa perusahaan melalui pembelian efek-efek baru yang ditawarkan atau yang diperdagangkan di pasar modal. Investor merupakan faktor penting hingga terjadinya transaksi di pasar modal. Menurut Fuady "pasar modal adalah tempat pertemuan antara penawaran dengan permintaan surat berharga/efek". ${ }^{2}$ Selanjutnya Darmadji mengatakan bahwa "pasar modal merupakan sebuah pasar tempat dana-dana modal seperti ekuitas dan utang diperdagangkan". 3

Berdasarkan ketentuan dalam Undang-Undang Nomor 8 Tahun 1995 Tentang Pasar Modal (selanjutnya disebut UUPM) para pihak yang terlibat secara aktif dalam kegiatan pasar modal adalah Emiten atau Perusahaan Terbuka sebagai pihak penyedia efek, investor sebagai penyedia dana atau pembeli efek dan pihak pemerintah selaku pengawas dan regulator di bidang pasar modal Otoritas Jasa Keuangan (OJK).

Keuntungan yang diharapkan dari berinvestasi saham adalah memperoleh return berupa capital gain dan deviden. Selain keuntungan, faktor resiko juga harus diperhatikan oleh investor apabila ingin berinvestasi saham. Pada umumnya resiko yang harus diperhatikan investor adalah resiko capital loss dan resiko likuiditas. Maka perlindungan hukum di pasar modal menjadi alat terpenting untuk melindungi kepentingan investor dan publik dari praktik yang merugikan baik yang dilakukan oleh emiten yang dinyatakan pailit. Perlindungan hukum yang seimbang antara debitor dan kreditur merupakan hal yang penting dalam menerapkan perlindungan dalam hukum kepailitan dan meningkatkan investasi baik nasional maupun internasional.

\section{RUMUSAN MASALAH}

Berdasarkan uraian diatas, maka penulis tertarik untuk membahas mengenai Bagaimanakah kedudukan dan bentuk perlindungan hukum bagi investor pasar modal dalam terjadi kepailitan pada perusahaan emiten?

\section{III.TUJUAN PENELITIAN}

Untuk menganalisis kedudukan dan bentuk perlindungan hukum bagi investor pasar modal dalam terjadi kepailitan pada perusahaan emiten.

\footnotetext{
${ }^{1}$ Undang-Undang Nomor 8 Tahun 1995 Tentang Pasar Modal Pasal 1 ayat (13).

${ }^{2}$ Munir Fuady. 2001. Pasar Modal Modern (Tinjauan Hukum). PT. Citra Aditiya Bhakti, Bandung.

${ }^{3}$ Darmadji, Tjiptono, dan H. M. Fachruddin, 2006, Pasar Modal di Indonesia: Pendekatan Tanya Jawab. Jakarta: Salemba Empat.
} 


\section{IV.TINJAUAN PUSTAKA}

\section{A. Pengertian Pasar Modal}

Menurut Undang-Undang No. 8 Tahun 1995 tentang Pasar Modal:

"Pasar Modal yaitu sebagai suatu kegiatan yang bersangkutan dengan penawaran umum dan perdagangan efek, perusahaan publik yang berkaitan dengan efek yang diterbitkannya, serta lembaga dan profesi yang berkaitan dengan efek."

Pengertian pasar modal menurut Fakhruddin: ${ }^{4}$

"Pasar modal (capital market) merupakan pasar untuk berbagai instrument keuangan jangka panjang yang bisa diperjualbelikan, baik dalam bentuk utang atau pun modal sendiri."

\section{B. Struktur Pasar Modal}

Organisasi terkait di Pasar Modal adalah sebagai berikut: ${ }^{5}$

1. Otoritas Jasa Keuangan memiliki kewenangan untuk elakukan pembinaan, pengaturan dan pengawasan Pasar Modal diIndonesia berdasarkan Undang-Undang Nomor 21 tahun 2011 tentang Otoritas Jasa Keuangan (selanjutnya disebut UU OJK).

2. Perusahaan memperoleh dana di Pasar Modal dengan melaksanakan penawaran umum atau investasi langsung (privateplacement).

Perusahaan ini dikenal sebagai emiten.

3. Self Regulatory Organizations (SRO), adalah organisasi yang memiliki kewenangan untuk membuat peraturan mengenai aktivitas usahanya. Yaitu :

a. Bursa Efek, adalah pihak yang menyelenggarakan dan menyediakan sistem penawaran jual dan beli efek. Yaitu Bursa Efek Indonesia (BEI)

b. Lembaga Kliring dan Penjaminan (LKP), adalah pihak yang menyelenggarakan jasa kliring dan penjaminan transaksi bursa agar terlaksana secara teratur, wajar, dan efisien. Lembaga yang telah memperoleh izin usaha sebagai LKP oleh Bapepam adalah PT. KPEI (PT. Kliring Penjaminan Efek Indonesia).

c. Lembaga Penyimpanan dan Penyelesaian (LPP), adalah pihak yang menyelenggarakan kegiatan custodian sentral bagi Bank Kustodian, Perusahaan Efek, dan pihak lain. Lembaga yang telah memperoleh izin usaha sebagai LPP oleh OJK adalah PT KSEI (PT. Kustodian Sentral Efek Indonesia).

d. Perusahaan Efek adalah perusahaan yang mempunyai aktifitas sebagai Perantara Pedagang Efek, Penjamin Emisi Efek, Manajer Investasi, atau gabungan dari ketiga kegiatan tersebut.

e. Penjamin Emisi Efek, adalah salah satu aktifitas pada perusahaan efek yang melakukan kontrak dengan emiten untuk melaksanakan penawaran umum dengan atau tanpa kewajiban untukmembeli sisa efek yang tidak terjual.

f. Perantara Pedagang Efek, adalah salah satu aktifitas pada perusahaan efek yang melakukan kegiatan usaha jual beli efek untuk kepentingan sendiri atau pihak lain.

g. Manajer Investasi, adalah pihak yang kegiatan usahanya mengelola portofolio efek dan portofolio investasi kolektif.

h. Penasihat Investasi, adalah pihak yang memberi nasihat kepada pihak lain mengenai penjualan atau pembelian efek.

4. Lembaga Penunjang Pasar Modal ${ }^{6}$

a. Biro Administrasi Efek, adalah pihak yang berdasarkan kontrak dengan emiten melaksanakan pencatatan pemilikan efek dan pembagian hak yang berkaitan dengan efek.

b. Kustodian adalah pihak yang memberikan jasa penitipan efek dan harta lainnya, termasuk menerima dividen, bunga, dan keuntungan lainnya, menyelesaikan transaksi efek, dan mewakili pemegang rekening yang menjadi nasabahnya.

c. Wali Amanat, adalah pihak yang mewakili kepentingan pemegang efek bersifat utang.

5. Profesi Penunjang Pasar Modal
a. Akuntan Publik
b. Notaris
c. Konsultan Hukum
d. Perusahaan Penilai

\section{Pengertian Kepailitan}

Menurut Undang-Undang Nomor 37 Tahun 2004 tentang Kepailitan dan Penundaan Kewajiban Pembayaran Utang Pasal 1 angka 1, Kepailitan adalah suatu sita umum terhadap sekuruh harta kekayaan milik debitur untuk kepentingan para krediturnya secara bersama sama yang timbul apabila debitur dinyatakan pailit oleh pengadilan yang berwenang untuk itu. ${ }^{7}$

\footnotetext{
${ }^{4}$ M. Fachruddin, 2001, Hukum Pasar Modal, Citra Adiya Bakti, Jakarta, hlm. 1.

${ }^{5}$ S. Husnan. 1992. "Efisiensi Pasar Modal Indonesia", Jurnal Ekonomi Indonesia, 24 April. hlm. 34

${ }^{6} \mathrm{Ibid}$

${ }^{7}$ Siti Anisah, 2008, Perlindungan Kepentingan Kreditor dan Debitor Dalam Hukum Kepailitan di Indonesia, Studi Putusan-Putusan Pengadilan, Total Media, Yogyakarta, hlm. 37
} 
Website : http://yustisia.unmermadiun.ac.id/index.php/yustisia

Secara tata bahasa, kepailitan berarti segala hal yang berhubungan dengan "pailit". Jika kita baca seluruh ketentuan yang dalam Undang-Undang Kepailitan, dapat ditemui satu rumusan atau ketentuan dalam Undang-Undang kepailitan yang menjelaskan pengertian maupun definisi dari kepailitan atau pailit. ${ }^{8}$

\section{Syarat-Syarat Mengajukan Permohonan Pernyataan Pailit}

Dalam Pasal 2 Ayat (1) Undang-Undang Nomor 37 Tahun 2004 tentang Kepailitan dan Penundaan Kewajiban Pembayaran Utang, syarat pengajuan pailit yaitu :

1. Debitor mempunyai dua atau lebih kreditor

2. Ada satu utang yang telah jatuh waktu dan dapat ditagih,

3. Kedua hal itu, dapat dibuktikan secarasederhana.

\section{METODE}

Metode penelitian yang penulis gunakan adalah penelitian hukum normatif. Penelitian inimenggunakan pendekatan perundang-undangan (statute approach) dan pendekatan konseptual (conceptual approach). Sumber dan Jenis Bahan Hukum adalah bahan hukum primer berupa peraturan perundang-undangan yaitu Undang-Undang Nomor 40 Tahun 2007 tentang Perseroan Terbatas, Undang-Undang Republik Indonesia Nomor 37 Tahun 2004 tentang Kepailitan dan Penundaan Kewajiban Pembayaran Utang, Undang-Undang Republik Indonesia Nomor 8 Tahun 1995 Tentang Pasar Modal dan Peraturan Otoritas Jasa Keuangan Nomor 26 /POJK.04/2017 Tentang Keterbukaan Informasi Bagi Emiten Atau Perusahaan Publik Yang Dimohonkan Pernyataan Pailit. Bahan Hukum Sekunder berupa bahan hukum yang berhubungan dengan sumber bahan hukum primer dan berkaitan dengan sumber hukum primer tersebut, antara lain adalah buku-buku dan jurnal yang berkaitan dengan perusahaan yang dinyatakan pailit.

\section{VI.DISKUSI DAN KESIMPULAN}

Berdasarkan Pasal 2 Ayat (4) Undang-Undang Nomor 37 Tahun 2004 tentang Kepailitan dan Penundaan Kewajiban Pembayaran Utang, menyebutkan dalam hal Debitor adalah Perusahaan efek, Bursa Efek, Lembaga Kliring dan Penjaminan, Lembaga Penyimpanan dan Penyelesaian, permohonan pernyataan pailit hanya dapat diajukan oleh Badan Pengawas Pasar Modal. Yang saat ini telah dialihkan kepada Otoritas Jasa Keuangan (OJK) berdasarkan Undang-Undang Nomor 21 tahun 2011 tentang Otoritas Jasa Keuangan. Akibat hukum kepailitan dari perusahaan terbuka atau emiten yang mengalami pailit meliputi seluruh kekayaan Debitor pada saat putusan pernyataan pailit diucapkan serta segala sesuatu yang diperoleh selama kepailitan. perusahaan public kehilangan hak kepengurusan dan penguasaan kekayaan sejak hari diucapkannya pernyataan pailit oleh hakim, segala pengurusan dan atau pemberesan harta perusahaan publik diberikan kepada kurator. Peran kurator dalam pengurusan sangat besar terhadap harta pailit, Kurator berwenang melaksanakan tugas pengurusan dan/atau pemberesan atas harta pailit sejak tanggal putusan pailit diucapkan meskipun terhadap putusan tersebut diajukan kasasi atau peninjauan kembali.

Pengurusan dan pemberesan harta pailit terhadap perusahaan publik sama dengan perusahaan biasa, seluruhnya diberikan kepada kurator sebagai pengurus dan pemberes harta pailit. Hanya saja dalam praktek, kurator harus bekerja sama dengan pengelola perdagangan bursa efek dan OJK. Dalam hal Emiten atau Perusahaan Publik diajukan ke pengadilan untuk dimohonkan pernyataan pailit, Emiten atau Perusahaan Publik wajib menyampaikan laporan mengenai hal tersebut kepada Otoritas Jasa Keuangan dan Bursa Efek dimana Efek Emiten atau Perusahaan Publik tercatat, sesegera mungkin paling lambat 2 (dua) hari kerja sejak Emiten atau Perusahaan Publik mengetahui adanya permohonan pernyataan pailit. ${ }^{9}$ Dalam hal ini Peran OJK hanya sebatas pelaporan dari emiten jika dimohonkan pailit, peran OJK sebagai pelindung dari investor pasar modal seharusnya tidak hanya membuat peraturan pada saat perusahaan akan melakukan go public saja tetapi juga harus memikirkan nasib investor apabila perusahaan emiten mengalami kepailitan, selain kurator dan hakim pengawas yang mengawasi pelaksanaan pemberesan dan atau pengurusan harta pailit, dalam perusahaan publik, OJK juga harus berperan sebagai lembaga pengawas terhadap tindakan kurator karena pemegang saham publik merupakan bagian dari kreditur perusahaan publik yang mempunyai kepentingan terhadap harta pailit. kedudukan investor pasar modal dalam hal terjadi kepailitan masih menjadi perdebatan apakah investor pasar modal bisa berkedudukan sebagai kreditur. Padahal Tidak dibenarkan seorang pemegang saham didudukan sebagai kreditor dalam proses kepailitan perusahaannya sendiri. Adapun seorang pemegang saham hanya akan menjadi kreditor pada saat proses kepailitan berujung pada proses likuidasi perseroan dan pemegang saham hanya mendapat bagian apabila semua kewajiban perseoroan kepada seluruh kreditor telah tepenuhi. Ketentuan dalam pasar modal belum mengatur mengenai ketentuan ini, Pemegang saham publik yang tidak turut serta dalam menjalankan perusahaan biasanya membeli saham perusahaan publik ini pada pasar perdana (primary market) dan pasar sekunder (secondary market) dimana saham-saham tersebut hanya dijual sebagian kecil saja, ${ }^{10}$ sehingga para pemegang saham publik yang diperoleh dari kedua pasar tersebut tidak terpengaruh dalam kebijaksanaan perusahaan.

\footnotetext{
${ }^{8}$ Ahmad Yani dan Gunawan Widjaja, 2004, Kepailitan, PT Raja Grafindo Persada, Jakarta,, hlm. 11

${ }^{9}$ Pasal 3 Peraturan Otoritas Jasa Keuangan Nomor 26 /POJK.04/2017 tentang Keterbukaan Informasi Bagi Emiten Atau Perusahaan Publik Yang Dimohonkan Pernyataan Pailit.

${ }^{10}$ UsmanMarzuki,dkk, 1999, Pengetahuan Dasar Pasar Modal. Jakarta: Institut Bankir Indonesia, him. 175
} 
Menurut penulis, para pemegang saham publik merupakan kreditur yang termasuk dalam kreditur bersaing (konkuren), merupakan kreditur yang mendapat bagian terakhir terhadap harta pailit seandainya ada deviden dari saham tersebut yang belum dibayar kepada para pemegang saham publik maka pemegang saham hanya bisa menunggu sisa dari harta pailit yang masih ada. Inilah kelemahan dari pemegang saham publik yang memiliki risiko besar terhadap saham yang dimilikinya, sehingga sebelum membeli saham publik, investor harus lebih berhati-hati dalam melakukan pilihan investasi dan peran OJK sebagai pengawas pasar modal.

Model perlindungan hukum yang berbasis keadilan bagi investor pasar modal jika perusahaan emiten mengalami kepailitan sangat diperlukan bagi investor pasar modal karena adalah pihak yang paling lemah jika terjadi kepailitan dalam perusahaan publik, karena merupakan kreditur konkuren yang mendapat perlakuan terakhir dari pembagian harta pailit dan itu pun jika masih ada tersisa. Menurut Jawn Rawls dalam bukunya A Theory of Justice menjelaskan inti teori keadilan sosial sebagai the difference principle dan the principle of fair equality of opportunity. ${ }^{11}$ Dimana pada intinya, the difference menjelaskan bahawa perbedaan sosial dan ekonomis harus diatur agar memberikan manfaat yang paling besar bagi mereka yang paling kurang beruntung. Sedangkan the principle of fair equality of opportunity menunjukkan pada mereka yang paling kurang mempunyai peluang untuk mencapai prospek kesejahteraan, pendapatan, dan otoritas. Mereka inilah yang harus diberi perlindungan khusus. ${ }^{12}$ Bentuk perlindungan hukum yang diperlukan adalah dengan memaksimalkan fungsi dan perana OJK sebagai pelindung para investor saham perusahaan emiten, dengan lembaga pengawas dalam hal terjadi kepailitan agar meminimalisir adanya kecurangan dari kurator dalam hal pengurusan harta pailit, terkait dengan kedudukan investor saham yang hanya sebagai kreditur konkuren. Dalam hal tindakan pencegahan sudah seharusnya OJK memberikan informasi-informasi yang akurat terkait dengan kinerja dan kondisi keuangan dari perusahaan publik, untuk menghindari risiko yang akan dihadapi investor saham. Selain itu hendaknya pihak-pihak terkait juga harus mengusahakan untukmencegah adanya kepailitan dari perusahaan emiten dengan membantu dan mengawasi kinerja perusahaan emiten, dengan melakukan upaya-upaya resktrukturisasi perusahaan emiten tersebut untuk menghindari kepailitan.

\section{DAFTAR PUSTAKA}

\section{A. Buku}

Ahmad Yani dan Gunawan Widjaja, 2004, Kepailitan, PT Raja Grafindo Persada, Jakarta. Carl Jiachim Friedrich, 2004, Filsafat Hukum perspektif Historis, Nusamedia, Bandung.

Darmadji, Tjiptono, dan H. M. Fachruddin, 2006 , Pasar Modal di Indonesia: Pendekatan Tanya Jawab. Jakarta: Salemba Empat.

John Rawls, 1973, A theory of Justice, London : Oxford University Press, alih bahasa Indonesia oleh Uzair Fauzan dan Heru Prasetyo, 2006, Teori keadilan, Pustaka Pelajar, Yogyakarta.

Munir Fuady. 2001. Pasar Modal Modern(TinjauanHukum). PT. Citra Aditiya Bhakti, Bandung.

M. Fachruddin, 2001, Hukum Pasar Modal, Citra Adiya Bakti, Jakarta.

S. Husnan. 1992. "Efisiensi Pasar Modal Indonesia", Jurnal Ekonomi Indonesia, 24 April.

Siti Anisah, 2008, Perlindungan Kepentingan Kreditor dan Debitor Dalam Hukum Kepailitan di Indonesia, Studi Putusan-Putusan Pengadilan, Total Media, Yogyakarta.

UsmanMarzuki,dkk, 1999, Pengetahuan Dasar Pasar Modal. Jakarta: Institut Bankir Indonesia.

\section{B. Peraturan Perundang-undangan}

Undang-Undang Nomor 8 Tahun 1995 Tentang Pasar Modal

Undang-Undang Nomor 40 Tahun 2007 tentang Perseroan Terbatas

Undang-Undang Nomor 37 Tahun 2004 tentang Kepailitan dan Penundaan Kewajiban Pembayaran Utang.

Peraturan Otoritas Jasa Keuangan Nomor 26 /POJK.04/2017 tentang Keterbukaan Informasi Bagi Emiten Atau Perusahaan Publik Yang Dimohonkan Pernyataan Pailit

\footnotetext{
${ }^{11}$ John Rawls, 1973, A theory of Justice, London : Oxford University Press, alih bahasa Indonesia oleh Uzair Fauzan dan Heru Prasetyo, 2006, Teori keadilan, Pustaka Pelajar, Yogyakarta, hal.42.

${ }^{12}$ Carl Jiachim Friedrich, 2004, Filsafat Hukum perspektif Historis, Nusamedia, Bandung, hal.26.
} 